\title{
COPD patients' medical care and support in Greece during financial crisis
}

This article was published in the following Dove Press journal:

International Journal of General Medicine

10 November 2016

Number of times this article has been viewed

\author{
George Mitonas' \\ Alexia Juvana ${ }^{2}$ \\ Zoe Daniil ${ }^{3}$ \\ Chryssa Hatzoglou ${ }^{4}$ \\ Konstantinos \\ Gourgoulianis ${ }^{3}$ \\ 'Diavata Health Center, Gennimatas \\ General Hospital, 2Papageorgiou \\ General Hospital, Thessaloniki, \\ ${ }^{3}$ Pulmonary Medicine Department, \\ University Hospital of Larissa, \\ ${ }^{4}$ Physiology Department, Medical \\ School, University of Thessaly, Larissa, \\ Greece
}

Background: The need to follow a multidisciplinary strategy in chronic obstructive pulmonary disease (COPD) management and rehabilitation in community settings in Greece raises significant questions, given the severe austerity measures being imposed at present. The aim of this study was to investigate the clinical profile of patients with COPD along with the care provided in rural community settings in Greece.

Methods: Two primary health care centers and 200 newly diagnosed patients over a 12-month period were involved in the study. A self-assessment questionnaire, including questions about smoking habits, the presence of comorbidities and chronic respiratory symptoms, as well as the COPD Assessment Test were used. Spirometry was performed with a dry spirometer. Obstructive spirometry was defined as forced expiratory volume in $1 \mathrm{~second} /$ forced vital capacity ratio $<0.7$, according to Global Initiative for Chronic Obstructive Lung Disease guidelines.

Results: Males comprised $70 \%$ of the sample, with cough and sputum being the prominent signs. Regarding COPD staging, $68.5 \%$ were classified in stages I/II. Arterial hypertension and coronary heart disease were the most common comorbidities. Current smokers accounted for $88.5 \%$, while $88 \%$ were heavy drinkers. A general practitioner made the diagnosis in $68.5 \%$ of the cases, among which offspring and spouses provided home care in $38 \%$ and $8 \%$ of the cases, respectively, while an informal caregiver other than a relative was reported in $34 \%$ of the cases. No caregiver (self-care) was reported in $20 \%$ of the cases. All patients of stage III and IV had a COPD Assessment Test score $>10$.

Conclusion: Patients with COPD dwelling in the community exhibit an overall mild-to-moderate type of COPD. General practitioner is in charge of COPD management. Informal caregiving is the major type of home care, with nonfamily members playing a significant role. The patients' profile permits limited optimism about their future perspective and urges for immediate action at primary care level.

Keywords: COPD, primary care, Greece, caregiver, general practitioner

\section{Introduction}

The chronic obstructive pulmonary disease (COPD) is defined as a preventable and treatable respiratory disease, which may cause serious systematic effects. ${ }^{1}$ It is currently the fifth highest cause of morbidity and mortality in the developed world, representing a substantial economic and social burden, with the worldwide prevalence of COPD estimated to be $\sim 1 \%$ of the total population. ${ }^{2,3}$ Given the underdiagnosis of COPD, the precise community burden is difficult to estimate. ${ }^{4}$ In Greece, it is believed that COPD prevalence ranges at $\sim 8 \%-10 \%$, being more prominent in males (11\%) than in females $(5 \%){ }^{5,6}$ Regarding the distribution of disease severity in primary care, mild and moderate type of disease
Correspondence: George Mitonas Diavata Health Center, Gennimatas General Hospital, 45 Smirnis Street, Pilea, 55535, Thessaloniki, Greece $\mathrm{Tel} / \mathrm{fax}+30$ 23। 0924477

Email gmitonas@yahoo.gr 
accounts for $\sim 80 \%$ of patients, while the major comorbidity is arterial hypertension and coronary heart disease. ${ }^{7}$ As smoking is the major causative factor, smoking cessation takes priority in the community setting, although it has proven quite difficult to achieve. Smoking rates are usually up to $30 \%-50 \%$ in patients with COPD, many of whom remain addicted to smoking, despite the awareness of the bad consequences of smoking. ${ }^{8-10}$

The fact that COPD is a systemic disease and its management demands a multidisciplinary strategy raises questions about the efficacy of COPD patients' care and rehabilitation in community settings in Greece in times of financial austerity as well as the current patient with COPD profile in Greece. The aim of this study was to investigate the clinical profile of patients with COPD visiting rural health care settings along with the care provided in rural community settings in Greece.

\section{Methods}

\section{Study design and participants}

The study was conducted at two rural primary health care settings (general practitioner [GP] practice centers) in the districts of Thessaly (Municipality of Larissa) and East Macedonia (Municipality of Thessaloniki), Greece, during a 12-month period (September 2013-September 2014). The research team, comprising a GP and an experienced nurse with special interest in COPD, visited each primary health care center during the first week of each month and conducted spirometry on every subject who volunteered to be examined. They were consecutive patients present on the days the team visited the health centers. The patients visited the health care settings for medication prescription and physical examination as outpatients. The study was approved by the University of Thessaly Ethics Committee. All 2,300 patients gave their written informed consent and 200 newly diagnosed patients were included in the study. After performing spirometry, the subjects were examined by the chest physician who made a diagnosis of COPD according to the existing COPD guidelines. The patients who were excluded from the study were those who had been previously diagnosed with COPD, inhaled any type of medication, presented a significant reversibility in spirometry, reported a history of other respiratory disease, or had suffered from upper or lower respiratory tract infection during the previous 4 weeks. The diagnosis of COPD was based on the patients' history of smoking and exposure to noxious particles or gases, other compatible symptoms, and forced expiratory volume in 1 second $\left(\mathrm{FEV}_{1}\right) /$ forced vital capacity $(\mathrm{FVC})$ ratio $<0.70$. Classification of COPD was based on postbronchodilation $\mathrm{FEV}_{1}$, according to the Global Initiative for Chronic Obstructive Lung Disease guidelines (stage I, mild COPD $\mathrm{FEV}_{1} \geq 80.0 \%$ predicted; stage II, moderate COPD $50.0 \% \leq \mathrm{FEV}_{1}<80.0 \%$ predicted; stage III, severe COPD $30.0 \% \leq \mathrm{FEV}_{1}<50.0 \%$; stage IV, very severe COPD $30.0 \% \leq \mathrm{FEV}_{1}$ or $\mathrm{FEV}_{1}<50.0 \%$ predicted with respiratory failure). The patients were also asked about their habits and their informal caregiver.

\section{Measurement tools}

A self-assessment questionnaire was first completed by all subjects, which included questions about smoking habits and the presence of comorbidities and chronic respiratory symptoms (ie, cough, sputum production, wheezing, and dyspnea). The identification of comorbidities was based on the health records of each patient and the types of medications received. The subjects were subsequently submitted to physical examination, including the assessment of their body mass index (BMI) and, finally, pre- and postbronchodilation spirometry. The BMI was calculated as the body weight divided by the square of height (expressed in $\mathrm{kg} / \mathrm{m}^{2}$ ). Patients were assigned to one of five BMI categories: normal weight (BMI <19-24.99), overweight (BMI 25-29.99), grade I obesity (BMI 30-34.99), grade II obesity (BMI 35-39.99), and grade III obesity $\left(\right.$ BMI >40). ${ }^{11}$ The subjects' smoking status and their physical activity were also recorded.

The COPD Assessment Test (CAT) was also used, ${ }^{12}$ which is designed to measure the impact of COPD on a person's life, and how this changes over time. The CAT is simple to administer, and aims to help clinicians manage a patient's COPD better. The total CAT score ranges from 0 to 40 . Higher scores denote a more severe impact of COPD on a patient's life. No target score represents the best achievable outcome, but a score over 10 indicates a possible impact on a patient's life.

Regarding alcohol consumption, according to the Dietary Guidelines for Americans, ${ }^{13}$ moderate drinking equals to up to one standard drink per day for females and up to two drinks per day for males.

A standard drink is equal to $355 \mathrm{~mL}$ beer ( $5 \%$ alcohol) or $150 \mathrm{~mL}$ glass of wine (12.5\% alcohol) or $45 \mathrm{~mL}$ of 80 proof liquor (40\% alcohol). ${ }^{13}$

\section{Spirometry}

Spirometry was performed with a dry spirometer (Spirolab II; MIR srl, Rome, Italy), according to the American Thoracic Society recommendations. Calibration checks were performed every morning, 30 minutes before the beginning of the spirometry program. Forced expiratory maneuvers were repeated until three reproducible acceptable tests were obtained and the best $\mathrm{FEV}_{1}, \mathrm{FVC}$, and $\mathrm{FEV}_{1}$ to $\mathrm{FVC}\left(\mathrm{FEV}_{1} / \mathrm{FVC}\right)$ ratio values were picked up from different curves from the set of 
the three reproducible and technically satisfactory maneuvers. Obstructive spirometry was defined as $\mathrm{FEV}_{1} / \mathrm{FVC}$ ratio $<0.7$.

\section{Statistical analysis/analysis of results}

Descriptive and inferential statistics were performed. Demographic and spirometry data are presented as mean \pm standard

Table I Profile of patients with COPD

\begin{tabular}{lll}
\hline Variables & $\mathbf{N}$ & $\%$ \\
\hline Sex & & \\
Males & 140 & 70.0 \\
Females & 60 & 30.0 \\
Total & 200 & 100.0 \\
Symptoms and signs & & \\
Cough & 58 & 29.0 \\
Sputum & 23 & 11.5 \\
Dyspnea & 7 & 3.5 \\
Cough and sputum & 71 & 35.5 \\
Cough and dyspnea & 41 & 20.5 \\
COPD stages & & \\
I & 33 & 16.5 \\
II & 104 & 52.0 \\
III & 54 & 27.0 \\
IV & 9 & 4.5 \\
Total & 200 & 100.0 \\
Comorbidities & & \\
AH & 28 & 23.5 \\
AH/OP & 19 & 9.5 \\
CHD/AH & 21 & 10.5 \\
CHD/DM & 5 & 2.5 \\
CHD/AH/DM & 57 & 28.5 \\
AH/DM & 25 & 12.5 \\
Depression & 18 & 9.0 \\
All the above & 21 & 10.5 \\
None & 6 & 3.0 \\
Total & 200 & 100 \\
\hline Abbreviation AH & 57 \\
\hline
\end{tabular}

Abbreviations: $\mathrm{AH}$, arterial hypertension; COPD, chronic obstructive pulmonary disease; CHD, coronary heart disease; DM, diabetes mellitus; OP, osteoporosis. deviation. A comparison of proportions was performed using chi-square test, whereas differences in numerical variables between groups were studied with analysis of variance and Bonferroni's post hoc test. $P$-values $<0.05$ were considered statistically significant. Data were analyzed using SPSS 22.0 for Windows (IBM Corporation, Armonk, NY, USA) and graphs were created with EXCEL 2013 (Microsoft, Washington, DC, USA) and Sigma plot 12.5 (Systat Software Inc., San Jose, CA, USA).

\section{Results}

Males accounted for $70 \%$ of the sample, with cough and sputum being the prominent symptoms. Regarding the COPD staging, the majority of patients $(68.5 \%)$ were classified as stage I/II, $27 \%$ belonged to stage III, and $4.5 \%$ to stage IV. Arterial hypertension and coronary heart disease were the most common comorbidities (Table 1). Mean age of the participants was $67.16 \pm 12.16$ years.

All patients at stages III and IV had a CAT score $>10$ (Figure 1).

One hundred and seventy-seven patients were current smokers $(88.5 \%), 61 \%$ of them consuming $>20$ cigarettes per day. Attempts to quit smoking were reported by $16.5 \%$ of them. The majority were heavy drinkers (more than two standard drinks per day). Walking was the most prevalent physical activity (Table 2).

A GP made the diagnosis in most cases (68.5\%) and the remaining were diagnosed by a pulmonologist. Seventy patients visited a pulmonologist regularly. Among them, 46 patients (65.7\%) visited the pulmonologist once every 3 months (Table 3 ).

Regarding the caregiver, offsprings and spouses provided home care in $38 \%$ and $8 \%$ of the cases, respectively, while an informal caregiver other than a relative was reported in

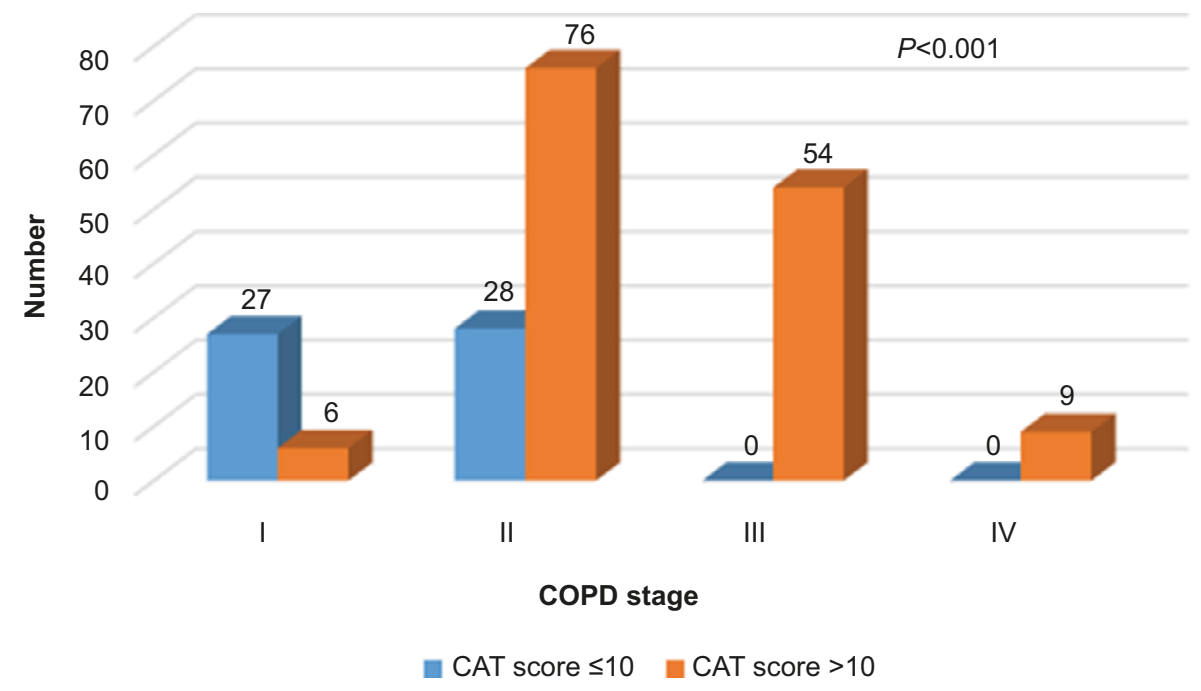

Figure I COPD stage and CAT score.

Abbreviations: COPD, chronic obstructive pulmonary disease; CAT, COPD Assessment Test. 
Table 2 Smoking, obesity, and physical activity

\begin{tabular}{|c|c|c|}
\hline Variables & $\mathbf{N}$ & $\%$ \\
\hline \multicolumn{3}{|l|}{ Smoking } \\
\hline Yes & 177 & 88.5 \\
\hline No & 23 & 11.5 \\
\hline Total & 200 & 100.0 \\
\hline \multicolumn{3}{|l|}{ Number of cigarettes } \\
\hline$>10$ & 44 & 22.0 \\
\hline$>20$ & 122 & 61.0 \\
\hline$<20$ & 34 & 17.0 \\
\hline Total & 200 & 100.0 \\
\hline \multicolumn{3}{|l|}{ Quit attempts/quit } \\
\hline Yes & 33 & 16.5 \\
\hline No & 167 & 83.5 \\
\hline Total & 200 & 100.0 \\
\hline \multicolumn{3}{|l|}{ Alcohol quantity* (glasses) } \\
\hline $0-1$ & 4 & 2.0 \\
\hline $2-3$ & 20 & 10.0 \\
\hline $3-4$ & 18 & 9.0 \\
\hline $5-6$ & 53 & 26.5 \\
\hline 7-9 & 64 & 32.0 \\
\hline$>10$ & 41 & 20.5 \\
\hline Total & 200 & 100.0 \\
\hline \multicolumn{3}{|l|}{ Obesity classification } \\
\hline I & 83 & 41.5 \\
\hline II & 54 & 27.0 \\
\hline III & 12 & 6.0 \\
\hline IV & 45 & 22.5 \\
\hline$\vee$ & 6 & 12.0 \\
\hline \multicolumn{3}{|l|}{ Physical activities } \\
\hline Walking & 98 & 49.0 \\
\hline Swimming & I & 0.5 \\
\hline Bicycling & 3 & 1.5 \\
\hline Swimming and walking & 59 & 29.5 \\
\hline Walking and bicycling & 34 & 17.0 \\
\hline Bicycling/swimming/walking & 5 & 2.5 \\
\hline
\end{tabular}

Note: *Per day - equivalent to one glass of wine (standard drink; $150 \mathrm{~mL}$ ).

Table $3 \mathrm{GP}$ and pulmonologist in the management of COPD

\begin{tabular}{lll}
\hline Variables & $\mathbf{N}$ & $\%$ \\
\hline Regular visits to pulmonologist & & \\
Once a month & 8 & 4.0 \\
Once every 3 months & 130 & 65.0 \\
Twice a year & 62 & 31.0 \\
Total & 200 & 100.0 \\
Satisfaction with GP & & \\
Yes & 137 & 68.5 \\
No & 63 & 31.5 \\
Total & 200 & 100.0 \\
\hline
\end{tabular}

Abbreviations: COPD, chronic obstructive pulmonary disease; GP, general practitioner.

$34 \%$ of the cases. No caregiver (self-care) was reported in $20 \%$ of the cases (Figure 2).

Patients who visited a pulmonologist twice a year had the best $\mathrm{FEV}_{1} / \mathrm{FVC}$ ratio. This difference is statistically significant when compared with those who visited the pulmonologist on a monthly basis (Figure 3 ).

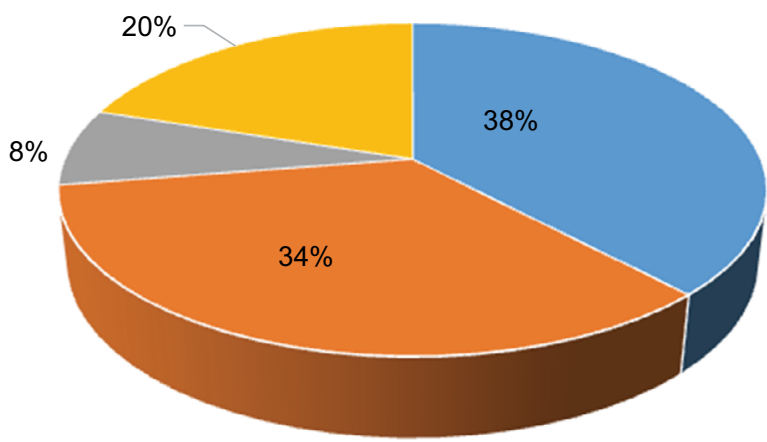

Offspring

Informal caregiver other than relative

Spouse

No caregiver

Figure 2 Distribution of informal caregivers.

The $\mathrm{FEV}_{1} / \mathrm{FVC}$ ratio correlated with CAT score: the patients with a CAT score $\leq 10$ had a statistically significantly higher $\mathrm{FEV}_{1} / \mathrm{FVC}$ ratio than those with a CAT score $>10$ (65.59 \pm 6.07 vs $59.64 \pm 11.24, P<0.001$ - data not shown). Also, when obesity was considered, those patients with obesity class II differed statistically significantly from those with obesity class IV $\left(\mathrm{FEV}_{1} / \mathrm{FVC}\right.$ ratio: $64.70 \pm 9.69$ vs $58.20 \pm 11.31, P=0.020$ - data not shown).

\section{Discussion}

The present study attempted to investigate the profile of patients with COPD in specific community settings in Greece. According to our results, patients with COPD dwelling in the community exhibited an overall mild-to-moderate type of COPD, were diagnosed with COPD at the beginning of their retirement age, had not quit smoking yet, and did not generally seem to have adopted a healthy lifestyle. The patients were generally satisfied with their GP, who was in charge of COPD management. However, the final diagnosis was conducted by the pulmonologist, since, depending on the severity of the disease, the patients regularly visited a pulmonologist. Informal caregiving was the major type of home care, with nonfamily members playing a significant role. This profile has raised severe concerns about the integrated care of patients with COPD and the efficacy of interventions at primary care level in Greece, especially in times of austerity.

The prevalence of COPD in the present study was prominent in males (ratio of males to females being 70:30). This is in accordance with the recent Greek study of Papaioannou et al, ${ }^{5}$ in which the smoking rates were lower and in agreement 


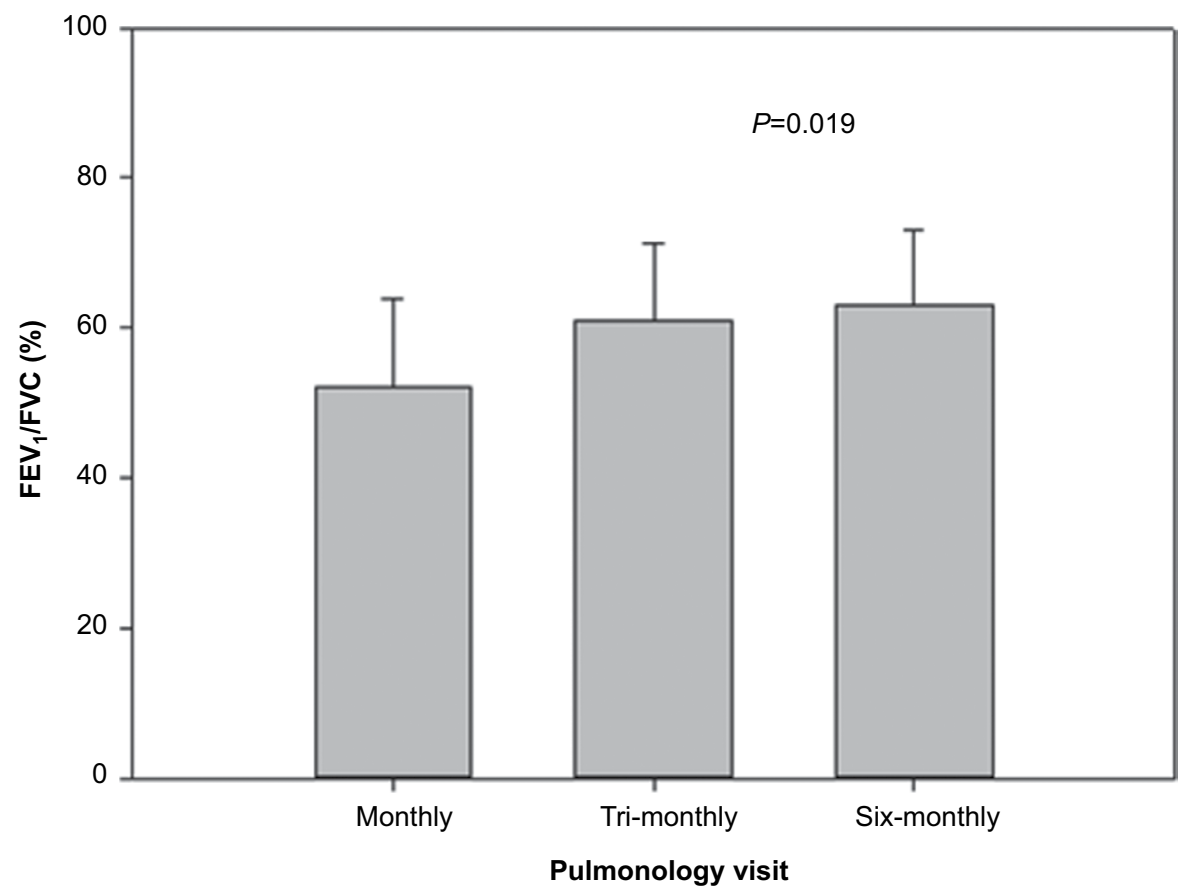

Figure $3 \mathrm{FEV} / \mathrm{FVC}$ depending on the frequency of pulmonologist visits.

Abbreviations: $\mathrm{FEV}_{1}$, forced expiratory volume in I second; FVC, forced vital capacity.

with the international data (around 50\%), while one-fifth of the patients were classified as stage IV. In our study, the COPD staging follows the international data showing lower rates at stage IV (around 5\%). ${ }^{2}$

A major concern is the efficacy of home care and the informal caregivers' adequacy of knowledge. As carers have often reported, they were unprepared to undertake a proper caring role and did not initially realize the nature of COPD and its long-term implications. Therefore, a well-planned multidisciplinary cooperation between health professionals and caregivers is more than necessary. ${ }^{14,15}$ As health services for the older patients with COPD are costly and nursing insurance only covers part of the bill, senior citizens often have to pay for home care themselves and a foreign caregiver is an alternative solution. ${ }^{16}$ Migrant care workers represent a considerable percentage of informal caregivers in the rural areas of Greece, which is a common practice in the Mediterranean countries that host a great amount of immigrants. Although migrant care workers are usually relatively well educated and socially advantaged in their country of origin, the global economic disparities have been the reason why many migrants can earn more in domestic and informal health care jobs in industrialized nations than in professional health care jobs in their country of origin. In the Mediterranean countries, an increasing percentage of families has been taking advantage of massive female migration and hiring migrant workers (particularly females) as home-based carers. ${ }^{17,18}$ However, worldwide, many foreign home attendants work without a specific legal entry and their services are questionable. ${ }^{19}$ Factors stemming from the immigrant care workers' ethnic/racial background, language barriers, and contextual factors, such as staff shortage in different care settings for older adults, may diminish the quality of care ${ }^{20}$ Governments should revise their policies on the issue of health care quality and provide necessary facilities to the patients with COPD.

Given the severe austerity in Greece, the necessity of a low-budget home care, which is highly demanding in the case of patient with COPD, may well account for the health care inequities observed, as well as for the difficult access to suitable facilities for these patients. The staffing of health services has been suboptimal during the past years, and any systematic interventions at the community level have been lacking. ${ }^{21,22}$

Another issue of great concern is smoking cessation. It is estimated that, in primary care, $25 \%-50 \%$ of patients with COPD are current smokers, ${ }^{5,9}$ a rate far behind the one in the present study. Nevertheless, only complete cessation of smoking slows the decline in lung function in COPD. Despite the objective restraints a GP faces in clinical practice, it is useful to remember that even a brief 3-minute period of counseling urging a smoker to quit can be effective, and should be conducted by any health care provider, even at a minimum. ${ }^{15}$ Successful quitting can be promoted by personalized cessation advice, based on lung function results. 
However, studies on patients with COPD in primary care show that primary care professionals' expectations should not be too high. Smoking cessation counseling in primary care accounts for $9 \%$ of patients with COPD quitting smoking, whereas had no intervention taken place, the percentage of those quitting smoking would have been only 4\%. ${ }^{5}$ A GP should take into consideration that every effort at quitting smoking is worthwhile and patients should be encouraged to keep trying. ${ }^{5,23}$ Quitting smoking, even when suffering from COPD, seems quite difficult and the right internal motivation to make the decision to quit is necessary. It has been reported that in the long term, personal factors, such as self-confidence and nicotine dependence, as well as social support play a crucial role in the success of efforts to quit smoking. Patients who continue to smoke regardless of their severe lung disease are highly nicotine dependent and need more intensive strategies..$^{9,10}$

In fact, an integrated COPD care in primary care, combining recall, spirometry, education and counseling, could improve the prevention and treatment of the disease and reduce its outbreaks. ${ }^{24,25}$ The high rate of comorbidities, along with an unhealthy clinical profile calls for urgent action. As hypertension and coronary heart disease are the major comorbidities, counseling with other specialists and a systematic follow-up in community settings should be a priority. ${ }^{26}$ The proper individualized management of patients with more severe symptoms by an outreach care specialist can prevent hospitalization. Other countries have a welldeveloped network of community care, including local patient support groups offering education, psychosocial support, and carer support. This network is highly respected by patients and can be accessed via national organizations. ${ }^{15,27}$ However, this is not the case in Greece and any attempt to initiate such a network at an elementary level is scarce and usually prevented by lack of funds.

Frontline prevention and early diagnosis are of great importance in the case of COPD. GPs see the vast majority of patients in the early stages of COPD. All primary health care professionals should be aware that COPD is an important problem with multiple economic and public health dimensions. GPs need to integrate simple diagnostic and counseling procedures into their practice to increase successful diagnosis and community rehabilitation rates. ${ }^{23,27,28}$

\section{Limitations and conclusion}

The present study is subject to some limitations. Patients come from two mountainous areas, where access to specialized health care facilities is rather limited and the burden of disease care lies mainly on primary care health professionals. One of the two areas belongs to districts with a low per capita income. Moreover, the answers in relation to physical activity were not quantified and there was no detailed recording of the monthly income, daily activities, and the severity of the comorbidities.

This cross-sectional study reveals the severe difficulties COPD patients face with their rehabilitation in community settings in Greece during times of austerity. The patients' profile permits limited optimism about their future perspective and urges for immediate action at primary care level. Our findings suggest that ongoing education is necessary, especially in the case of GPs. Despite difficult circumstances and limited resources, GPs and specialists, where available, should systematically reinforce their counseling methods and adopt appropriate home care approaches.

\section{Author contributions}

All authors contributed toward data analysis, drafting and revising the paper and agree to be accountable for all aspects of the work.

\section{Disclosure}

The authors report no conflicts of interest in this work.

\section{References}

1. Global Initiative for Chronic Obstructive Lung Disease (GOLD). Available from: www.goldcopd.com. Accessed May 20, 2015.

2. Schermer T, van Weel C, Barten F, et al. Prevention and management of chronic obstructive pulmonary disease (COPD) in primary care: position paper of the European Forum for Primary Care. Qual Prim Care. 2008;16(5):363-377.

3. Viegi G, Pistelli F, Sherrill DL, Maio S, Baldacci S, Carrozzi L. Definition, epidemiology and natural history of COPD. Eur Respir J. 2007;30(5):993-1013.

4. Lamprecht B, Soriano JB, Studnicka M, et al; BOLD Collaborative Research Group, the EPI-SCAN Team, the PLATINO Team, and the PREPOCOL Study Group. Determinants of underdiagnosis of COPD in national and international surveys. Chest. 2015;148:971-985.

5. Papaioannou AI, Bania E, Alexopoulos EC, Mitsiki E, Malli F, Gourgoulianis KI. Sex discrepancies in COPD patients and burden of the disease in females: a nationwide study in Greece (Greek Obstructive Lung Disease Epidemiology and health ecoNomics: GOLDEN study). Int J Chron Obstruct Pulmon Dis. 2014;9:203-213.

6. Tzanakis N, Anagnostopoulou U, Filaditaki V, Christaki P, Siafakas N; COPD group of the Hellenic Thoracic Society. Prevalence of COPD in Greece. Chest. 2004;125(3):892-900.

7. Hoogendoorn M, Feenstra TL, Schermer TR, Hesselink AE, Ruttenvan Mölken MP. Severity distribution of chronic obstructive pulmonary disease (COPD) in Dutch general practice. Respir Med. 2006; 100(1):83-86.

8. Hilberink SR. Effectiveness of a smoking cessation programme for COPD (SMOCC) in routine general practice. Eur Respir J Suppl. 2005; 49:245s.

9. Jiménez-Ruiz CA, Fagerström KO. Smoking cessation treatment for COPD smokers: the role of counselling. Monaldi Arch Chest Dis. 2013;79(1):33-37. 
10. Eklund BM, Nilsson S, Hedman L, Lindberg I. Why do smokers diagnosed with COPD not quit smoking? - A qualitative study. Tob Induc Dis. 2012;10(1):17.

11. Patil H, Astik G, House JA, O’Keefe JH, Main ML. Prevalence of grade II and III obesity among patients hospitalized with cardiovascular diagnoses in 2002 v. 2009. Mo Med. 2012;109(5):397-401.

12. Jones PW, Harding G, Berry P, Wiklund I, Chen WH, Kline Leidy N. Development and first validation of the COPD Assessment Test. Eur Respir J. 2009;34(3):648-654.

13. NIH: National Institute on Alcohol Abuse and Alcoholism. Available from: http:/www.niaaa.nih.gov/alcohol-health/overview-alcoholconsumption/moderate-binge-drinking. Accessed October 25, 2016.

14. Spence A, Hasson F, Waldron M, et al. Active carers: living with chronic obstructive pulmonary disease. Int J Palliat Nurs. 2008;14(8): 368-372.

15. Walters J. COPD - Diagnosis, management and the role of the GP. Aust Fam Physician. 2010;39(3):100-103.

16. Yeoh BS, Huang S. Foreign domestic workers and home-based care for elders in Singapore. J Aging Soc Policy. 2010;22(1):69-88.

17. Gul O, Pierrette HS. Migrant women, domestic work, and the new gender order: comments on the European case. In: Helma Lutz, editor. Migration and Domestic Work: A European Perspective on a Global Theme. Aldershot, UK: Ashgate Publishing, Ltd.; 2008: 195-208.

18. European Commission. Long-Term Care for the Elderly Provisions and Providers in 33 European Countries. Luxembourg: Publications Office of the European Union; 2012.

19. Cohen-Mansfield J, Garms-Homolová V, Bentwich M. Migrant home attendants: regulation and practice in 7 countries. Am J Public Health. 2013;103(12):e30-39.
20. Bourgeault IL, Atanackovic J, Rashid A, Parpia R. Relations between immigrant care workers and older persons in home and long-term care. Can J Aging. 2010;29(1):109-118.

21. Niakas D. Greek economic crisis and health care reforms: correcting the wrong prescription. Int J Health Serv. 2013;43:597-602.

22. Ifanti AA, Argyriou AA, Kalofonou FH, Kalofonos HP. Financial crisis and austerity measures in Greece: their impact on health promotion policies and public health care. Health Policy. 2013;113(1-2): $8-12$.

23. Radin A, Cote C. Primary care of the patient with chronic obstructive pulmonary disease-part 1: frontline prevention and early diagnosis. Am J Med. 2008;121(7):S3-12.

24. Meulepas MA, Jacobs JE, Smeenk FW, et al. Effect of an integrated primary care model on the management of middle-aged and old patients with obstructive lung diseases. Scand J Prim Health Care. 2007;25(3):186-192.

25. Todd DC, McIvor RA, Pugsley SO, Cox G. Approach to chronic obstructive pulmonary disease in primary care. Can Fam Physician. 2008; 54(5):706-711.

26. Minas M, Verrou-Katsarou I, Mystridou P, Apostolidou E, Hatzoglou C, Gourgoulianis KI. Two-year mortality of patients with COPD in primary health care: an observational study. Int J Gen Med. 2012; 5:815-822.

27. Aisanov Z, Bai C, Bauerle O, et al. Primary care physician perceptions on the diagnosis and management of chronic obstructive pulmonary disease in diverse regions of the world. Int J Chron Obstruct Pulmon Dis. 2012;7:271-282.

28. Bolton CE, Ionescu AA, Edwards PH, Faulkner TA, Edwards SM, Shale DJ. Attaining a correct diagnosis of COPD in general practice. Respir Med. 2005;99(4):493-500.
International Journal of General Medicine

\section{Publish your work in this journal}

The International Journal of General Medicine is an international peer-reviewed open-access journal that focuses on general and internal medicine, pathogenesis, epidemiology, diagnosis, monitoring and treatment protocols. The journal is characterized by the rapid reporting of reviews, original research and clinical studies across all disease areas.

\section{Dovepress}

The manuscript management system is completely online and includes a very quick and fair peer-review system, which is all easy to use. Visit http://www.dovepress.com/testimonials.php to read real quotes from published authors.

Submit your manuscript here: https://www.dovepress.com/international-journal-of-general-medicine-journal 